\title{
Article \\ Crystallization Behaviors of Composites Comprising Biodegradable Polyester and Functional Nucleation Agent
}

\author{
Li-Ting Lee ${ }^{1, *}$, Hsiang-Yun Tseng ${ }^{1}$ and Tzi-Yi Wu ${ }^{2}$ (D) \\ 1 Department of Materials Science and Engineering, Feng Chia University, Taichung 40724, Taiwan; \\ sam_06412@yahoo.com.tw \\ 2 Department of Chemical and Materials Engineering, National Yunlin University of Science and Technology, \\ Yunlin 64002, Taiwan; wuty@gemail.yuntech.edu.tw \\ * Correspondence: ltlee@fcu.edu.tw; Tel.: +886-4-2451-7250 (ext. 5306)
}

check for

updates

Citation: Lee, L.-T.; Tseng, H.-Y.; Wu, T.-Y. Crystallization Behaviors of

Composites Comprising

Biodegradable Polyester and

Functional Nucleation Agent. Crystals 2021, 11, 1260. https://doi.org/

$10.3390 /$ cryst11101260

Academic Editors:

Jesús Sanmartín-Matalobos and Eamor M. Woo

Received: 10 September 2021

Accepted: 16 October 2021

Published: 18 October 2021

Publisher's Note: MDPI stays neutra with regard to jurisdictional claims in published maps and institutional affiliations.

Copyright: (c) 2021 by the authors. Licensee MDPI, Basel, Switzerland. This article is an open access article distributed under the terms and conditions of the Creative Commons Attribution (CC BY) license (https:// creativecommons.org/licenses/by/ $4.0 /)$

\begin{abstract}
In this study, a thorough study of the crystallization behaviors of the biodegradable polymer composites of poly(ethylene succinate) (PESu) and hexagonal boron nitride (h-BN) was carried out. We found that $\mathrm{h}-\mathrm{BN}$ had a significant nucleation effect on crystallization behaviors. DSC isothermal crystallization results demonstrated that the crystallization time of the PESu/h-BN composites became shorter after adding $\mathrm{h}-\mathrm{BN}$. The rate constant $\mathrm{k}$ values calculated from the Avrami equation were larger for the composites, demonstrating that PESu's crystallization rate was increased by adding h-BN. TEM and SEM images showed the well-dispersed h-BN in the PESu matrix. Optical microscopy revealed that the PESu/h-BN composites formed more and smaller spherulites than neat PESu did, which confirmed that h-BN caused the nucleation effect. $\mathrm{H}-\mathrm{BN}$ also accelerated nonisothermal crystallization kinetics. We discussed the behaviors of the Mo model, which demonstrated that h-BN promoted the kinetics of non-isothermal crystallization. The XRD diffraction patterns showed that h-BN in the composites would not obviously change the crystalline structure of PESu.
\end{abstract}

Keywords: crystallization behaviors; biodegradable polymer; poly(ethylene succinate); polymer composite; hexagonal boron nitride

\section{Introduction}

In order to meet the different needs of life, different types of polymeric materials have been developed. In recent years, the problem of plastic waste has affected human life. To solve the issue of plastic waste, biodegradable polymers have been developed [1-8]. In general, biodegradable polymers can decompose in the natural environment and may be non-toxic during the manufacturing process.

The investigation into the crystallization behaviors of biodegradable polyesters is a crucial topic. The crystallization behaviors of general biodegradable polyesters such as poly(lactide) (PLA), poly( $\varepsilon$-caprolactone) (PCL), poly(ethylene adipate) (PEA), poly(butylene adipate) (PBA), and poly(butylene succinate) (PBSu) have been discussed in the literature [9-18], which found that the crystallization rates of these polymers can be increased by nucleation agents such as orotic acid, polyhedral oligomeric silsesquioxanes, graphite oxide, calcium carbonate, the stereocomplex of PLA, the inclusion complex of cyclodextrin, and biocompatible diamide. Semi-crystalline poly(ethylene succinate) (PESu) is also a biodegradable polyester which can be polymerized with the polycondensation method by aliphatic diacid and aliphatic diol such as succinic acid and 1,2-ethanediol, respectively [19-21]. The heat and mechanical properties of PESu are attractive and comparable to those of polyethylene and polypropylene [22]. Another characteristic of PESu which still needs to be reinforced is that of its slow crystallization rate. The fillers could improve the nucleation effect to increase the crystallization rate of PESu. The PESu's physical properties and crystallization rate can be enhanced by adding useful fillers such as graphene and 
$\mathrm{SiO}_{2}$ [23-26]. Exploring new fillers that can improve the properties of PESu will be one of the focuses in PESu's future development.

In order to enhance the nucleation effect of crystallization, nucleating agents (NAs) are usually added into polymeric systems [27-30]. Hexagonal boron nitride (h-BN) shows good mechanical, thermal conductivity, and thermal stability properties [31]. Regarding its structural features, h-BN is very similar to graphene [31], showing a two-dimensional structural feature. The addition of $\mathrm{h}-\mathrm{BN}$ can enhance the application of polymers in biomedicine and packaging materials [32-35]. On the other hand, h-BN has also been added to binary or ternary polymer composites to introduce its nucleation effect and affect their crystallization properties [36,37]. The binary poly(3-hydroxybutyrate-co-4-hydroxybutyrate)/h-BN and ternary PLLA/PEA/h-BN composites all showed an enhanced crystallization rate because of the presence of h-BN $[36,37]$. Based on the above descriptions, it can be expected that the effect of adding h-BN to PESu may be similar to the nucleation effect of adding graphene and $\mathrm{SiO}_{2}$ to $\mathrm{PESu}$, which can promote the crystallization of PESu. However, unlike the addition of graphene and $\mathrm{SiO}_{2}$, the addition of h-BN can expand the different characteristics of PESu in future applications such as thermal conductivity.

Since h-BN shows superior functionalities such as thermal conductivity and thermal stability, and its addition to polymers may also improve the crystallization of polymers, $\mathrm{h}$ $\mathrm{BN}$ is a favorable candidate filler for enhancing the crystallization and functionality of PESu. $\mathrm{PESu} / \mathrm{h}-\mathrm{BN}$ composites are composites that are worthy of being explored and discussed. Until now, there has not been a complete and in-depth study of the crystallization kinetics of PESu/h-BN composites. In this study, the crystallization and the relevant kinetics of PESu/h-BN composites were discussed. With the compositional range from $0.5 \mathrm{wt} \%$ to $3 \mathrm{wt} \%$ of h-BN, the crystallization rate of PESu can be gradually increased. A very small amount of h-BN can efficiently improve the crystallization of PESu. H-BN caused a significant nucleation effect on the crystallization of PESu. The complete discussion of the crystallization kinetics of the composites in this study is expected to be helpful in the development of green biodegradable polymers in the future.

\section{Experimental}

\subsection{Materials and Preparation}

For our study, we purchased biodegradable poly(ethylene succinate) (PESu) (with a molecular weight of $10,000 \mathrm{~g} / \mathrm{mol}$ ) and the nucleating agent hexagonal boron nitride (h-BN) from Sigma-Aldrich (Sigma-Aldrich, St. Louis, MO, USA). In order to manufacture the composites, h-BN was first well dispersed in the chloroform solution (30 min of ultrasonic treatment), followed by the addition of PESu into the h-BN solution with continuous stirring for over $3 \mathrm{~h}$. The ratios of PESu to h-BN were 100/0, 99.5/0.5, 99/1, 98/2, 97/3 (weight ratio) and the concentration of PESu and h-BN in chloroform was approximately $1 \sim 3 \mathrm{wt} . \%$. The prepared solutions of PESu and h-BN in chloroform were then casted at $45^{\circ} \mathrm{C}$ for $8 \mathrm{~h}$ to allow the evaporation of the solvent and the formation of composite films. The casted films were finally degassed in a vacuum oven at $60^{\circ} \mathrm{C}$ for at least 3 days.

\subsection{Apparatus and Procedures}

\subsubsection{Polarized Optical Microscopy (POM)}

The crystallization images were resolved through an Olympus CX41-polarized optical microscope-manufactured by Olympus in Tokyo, Japan. The Linkam THM-600 hot stage was also used to control the crystallization temperature. Composites prepared by solutioncasting were first melted at $130^{\circ} \mathrm{C}$. Afterward, they were transferred to the crystallization temperature for microscopic observation.

\subsubsection{Scanning Electron Microscopy (SEM)}

Scanning electron microscopy (Hitachi S3400, Hitachi, Tokyo, Japan) was used to observe the sample cross-section. In order to enhance the electrical and thermal conductivity, we coated the sample with gold by vapor deposition before the SEM observation. 


\subsubsection{Transmission Electron Microscopy (TEM)}

The composite morphology was also characterized with the higher resolution transmission electron microscopy (JEM-1400, JEOL, Peabody, MA, USA). We sought to detect h-BN's dispersion in composites by TEM observation under higher magnification. The thin films for TEM observation were prepared by casting the PESu/h-BN solution onto the copper grid.

\subsubsection{Differential Scanning Calorimetry (DSC)}

The DSC we used was the Perkin-Ekmer 8500-made by Perkin-Elmer in Waltham, $\mathrm{MA}$, USA. The isothermal and non-isothermal crystallization behaviors of the PESu/h-BN composites were investigated. For isothermal crystallization, the PESu/h-BN composites were crystallized under crystallization temperatures $\left(\mathrm{T}_{\mathrm{c}}\right)$ of $50{ }^{\circ} \mathrm{C}, 52{ }^{\circ} \mathrm{C}, 54{ }^{\circ} \mathrm{C}$ and $56^{\circ} \mathrm{C}$. Before isothermal crystallization, all samples were treated by the same melting and quenching process (melted at $130{ }^{\circ} \mathrm{C}$ for $5 \mathrm{~min}$, then quenched) so that their thermal histories could be eliminated. For non-isothermal crystallization, the composites were first heated to $130^{\circ} \mathrm{C}$, and then cooled at different rates $\left(4,6,8\right.$ and $\left.10^{\circ} \mathrm{C} / \mathrm{min}\right)$ to observe and analyze the non-isothermal crystallization.

\subsubsection{Wide-Angle X-ray Diffraction (WAXD)}

WAXD was also used for studying the composites of PESu and h-BN. A Bruker D2 Advance XRD made by Bruker in MA, USA, was applied. The crystalline structures of the composites were detected with the scanning angle range from $2 \theta=5^{\circ}$ to $50^{\circ}$ accompanying the scanning condition of $1^{\circ} /$ minute.

\section{Results and Discussion}

\subsection{Morphological Observation}

Generally, the SEM and TEM can provide high-resolution images to identify the morphology of composites. We applied SEM and TEM to determine the morphology. SEM images of the representative composites (PESu/h-BN =100/0, 99/1, and 97/3) are shown in Figure 1. These display that h-BN was well dispersed in each composition without obvious agglomeration. The particle size of $\mathrm{h}-\mathrm{BN}$ is below mesoscopic dimension, and its average particle size is approximately several hundred nanometers. We further characterized the morphology through TEM. The TEM images are shown in Figure 2. Two representative PESu/h-BN compositions (99/1 and 97/3) were demonstrated for showing their relevant morphologies. In the TEM images with higher resolution, it could be seen that h-BNs are slightly stacked in layers, and in each piece of the h-BN sheet, the lateral size is approximately several hundred nanometers. The SEM and TEM images indicated that h-BN can be finely dispersed in the PESu matrix.

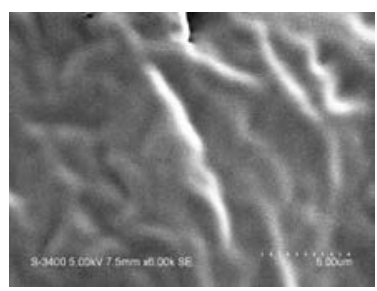

(a)

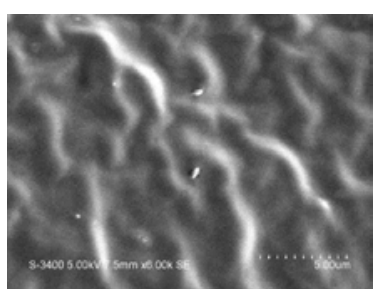

(b)

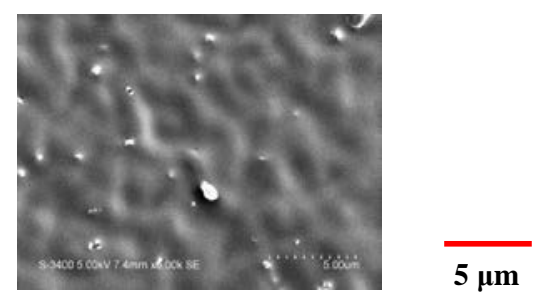

(c)

Figure 1. SEM cross-section images of PESu/h-BN composites with different compositions: (a) 100/0; (b) 99/1; and (c) 97/3. 


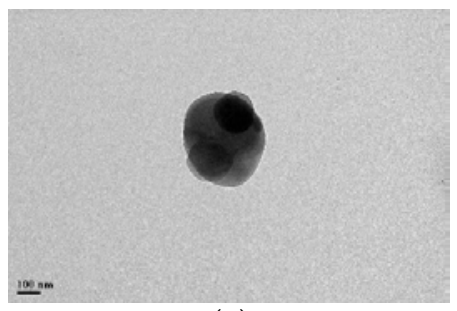

(a)

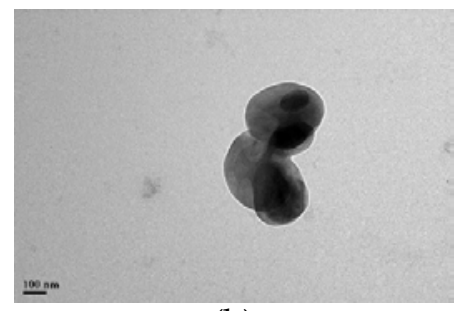

(b) $\overline{100} \mathbf{~ n m}$

Figure 2. TEM images of PESu/h-BN compositions with the compositions: (a) PESu/h-BN = 99/1; and (b) PESu/h-BN = 97/3 (magnification: 10000X, working voltage: $100 \mathrm{kV}$ ).

\subsection{Isothermal Crystallization Investigation of PESu/h-BN Composites}

This study explored the effect of adding h-BN on the isothermal crystallization of PESu. Firstly, DSC was used to observe the isothermal crystallization behaviors of the composites. Figure 3 shows the isothermal crystallization results (Tc's $=50,52,54$, and $56^{\circ} \mathrm{C}$ ). It was observed that, for each composition, the phenomena occurring at different crystallization temperatures were similar. In the presence of $\mathrm{h}-\mathrm{BN}$, all $\mathrm{PESu} / \mathrm{h}-\mathrm{BN}$ composites showed a relatively short crystallization time. In addition, as the content of h-BN increased, the crystallization time gradually shortened, which means that the presence of $\mathrm{h}-\mathrm{BN}$ can reduce the crystallization time of PESu. H-BN can enhance the isothermal crystallization behaviors in the composites.

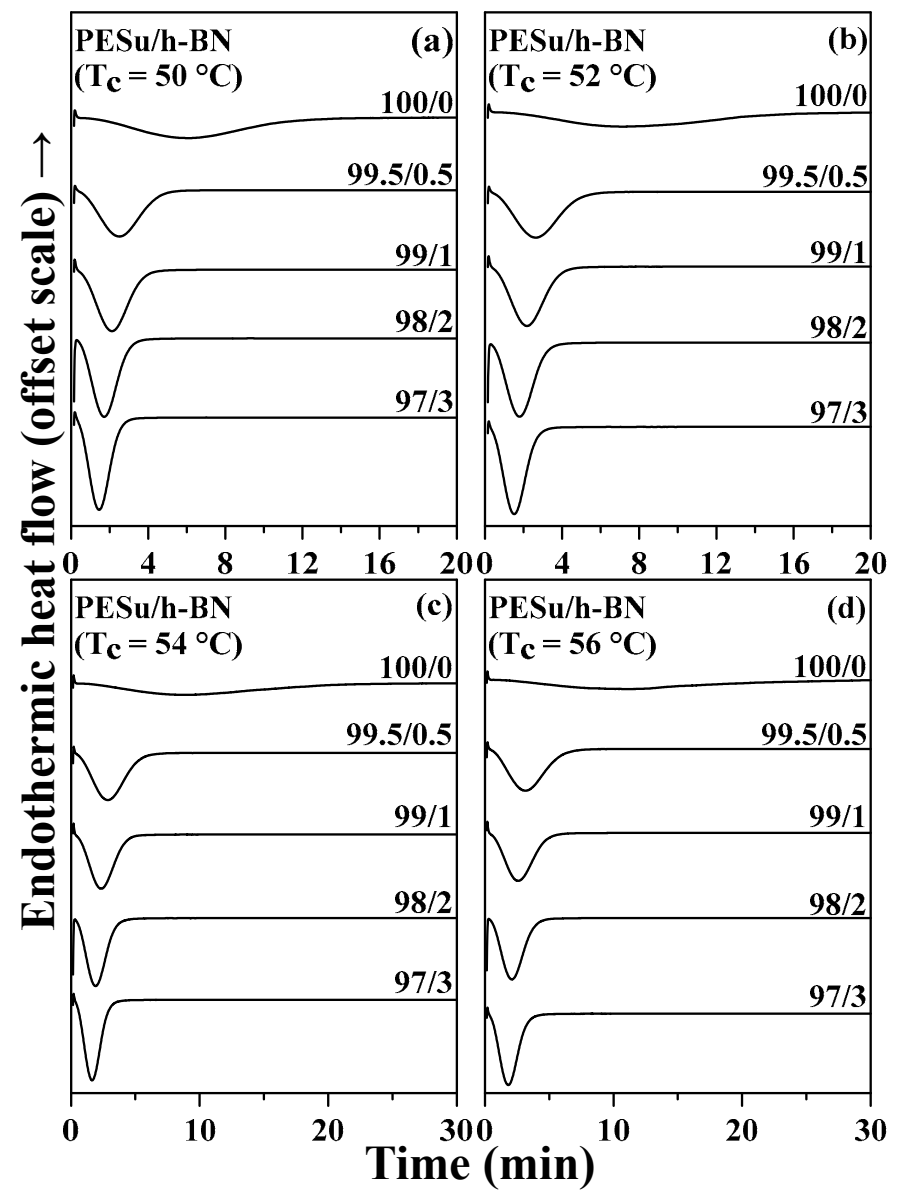

Figure 3. Isothermal crystallization thermograms of PESu/h-BN composites at: $(\mathbf{a}) \mathrm{T}_{\mathrm{C}}=50{ }^{\circ} \mathrm{C}$; (b) $\mathrm{T}_{\mathrm{C}}=52{ }^{\circ} \mathrm{C} ;$ (c) $\mathrm{T}_{\mathrm{C}}=54{ }^{\circ} \mathrm{C}$; and (d) $\mathrm{T}_{\mathrm{C}}=56{ }^{\circ} \mathrm{C}$. 
We further used the Avrami equation [37] to discuss isothermal crystallization behaviors. It connects the relationship among the degree of crystallization $\left(X_{t}\right)$, the rate constant (k), and the Avrami exponent (n). The Avrami equation and the logarithmic form of the Avrami equation are demonstrated below:

$$
\begin{gathered}
1-\mathrm{X}_{\mathrm{t}}=\exp \left(-\mathrm{kt}^{\mathrm{n}}\right) \\
\log \left[-\ln \left(1-\mathrm{X}_{\mathrm{t}}\right)\right]=\log \mathrm{k}+\mathrm{nlog} \mathrm{t}
\end{gathered}
$$

when the $\log \left[-\ln \left(1-X_{t}\right)\right]$ versus $\log (t)$ plot exhibits a linear relationship, $k$ and $n$ are the slope and intercept the plot, respectively. Figure 4 demonstrates the Avrami plots for related composites. The compositions of the composites are PESu $/ \mathrm{h}-\mathrm{BN}=100 / 0,99.5 / 0.5$, $99 / 1,98 / 2$, and $97 / 3$. From the results in Figure 4, it can be seen that the Avrami equation can form good fitting results for the PESu/h-BN composites. All fitting results display the linear relationship.
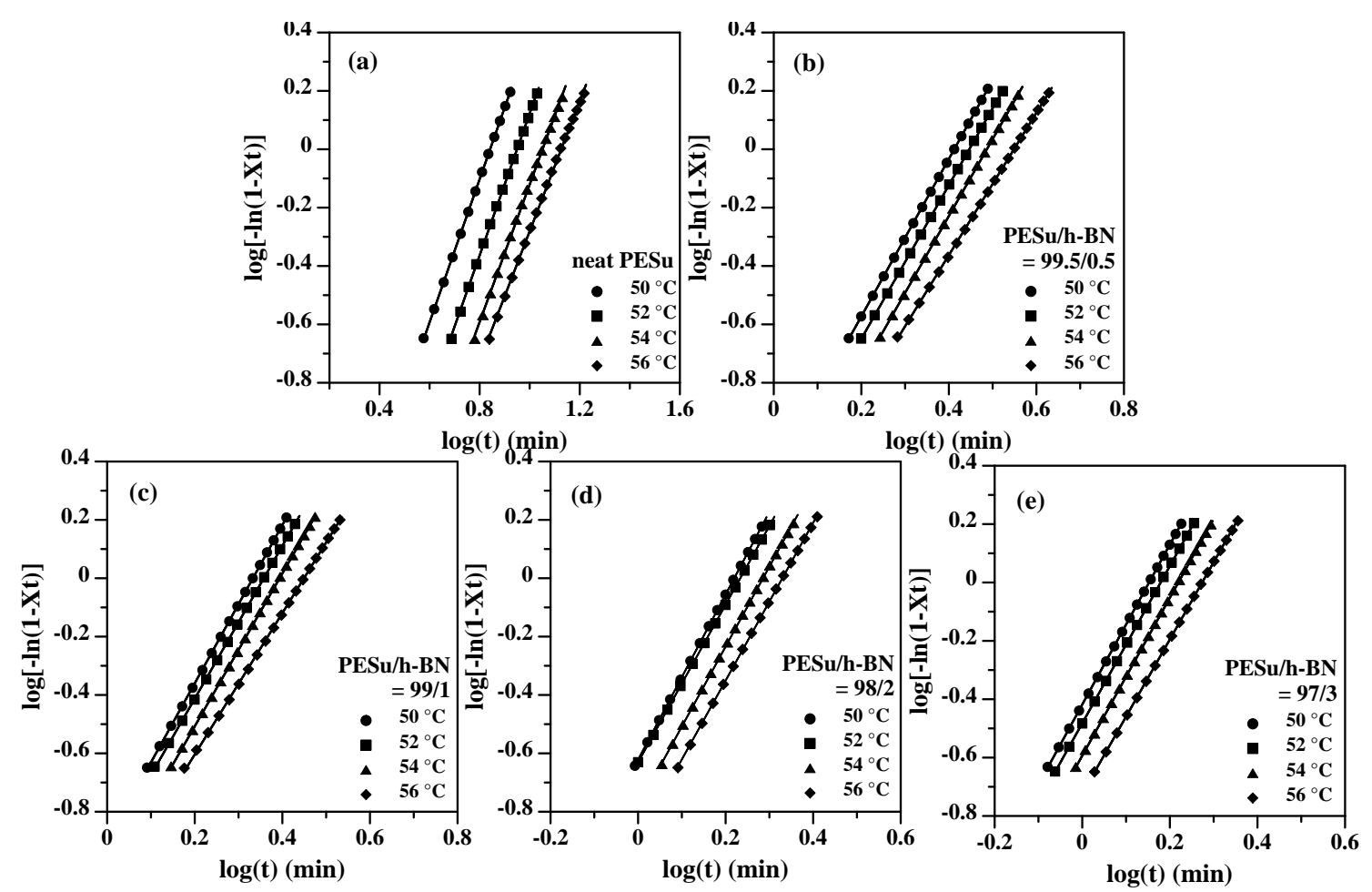

Figure 4. The Avrami plots for isothermal crystallization for various PESu/h-BN composites: (a) 100/0; (b) 99.5/0.5; (c) 99/1; (d) $98 / 2$; and (e) $97 / 3$.

The related kinetic parameters estimated by the Avrami equation are displayed in Table 1. It could be seen that the value of $n$ is between 2 and 3 for the PESu/h-BN composites, which means that adding h-BN to PESu had no influence on PESu's crystallization mechanism. It can be found that the $\mathrm{k}$ value increased with the increase in the $\mathrm{h}-\mathrm{BN}$ content. A similar tendency is also demonstrated in Figure 5 with the k-vs-h-BN content plots. In the $\mathrm{PESu} / \mathrm{h}-\mathrm{BN}$ composites, h-BN may provide additional nucleation sites for PESu, leading to a preferable crystallization rate for the composites. The h-BN in the composites can enhance the nucleation effect of crystallization, so that the crystallization rate of isothermal crystallization can therefore be increased. 
Table 1. The Avrami kinetic parameters for the isothermal crystallization behaviors of PESu/hBN composites.

\begin{tabular}{|c|c|c|c|}
\hline PESu/h-BN (wt.\%) & $\mathbf{T}_{\mathrm{c}}\left({ }^{\circ} \mathrm{C}\right)$ & $\mathbf{n}$ & $\mathbf{k}\left(\min ^{-n}\right)$ \\
\hline \multirow{4}{*}{$100 / 0$} & 50 & 2.45 & 0.0086 \\
\hline & 52 & 2.43 & 0.0049 \\
\hline & 54 & 2.35 & 0.0034 \\
\hline & 56 & 2.23 & 0.0031 \\
\hline \multirow{4}{*}{$99.5 / 0.5$} & 50 & 2.70 & 0.0772 \\
\hline & 52 & 2.63 & 0.0667 \\
\hline & 54 & 2.63 & 0.0522 \\
\hline & 56 & 2.44 & 0.0459 \\
\hline \multirow{4}{*}{$99 / 1$} & 50 & 2.71 & 0.1253 \\
\hline & 52 & 2.62 & 0.1159 \\
\hline & 54 & 2.62 & 0.0931 \\
\hline & 56 & 2.42 & 0.0676 \\
\hline \multirow{4}{*}{$98 / 2$} & 50 & 2.83 & 0.2389 \\
\hline & 52 & 2.70 & 0.2340 \\
\hline & 54 & 2.74 & 0.1652 \\
\hline & 56 & 2.70 & 0.1285 \\
\hline \multirow{4}{*}{$97 / 3$} & 50 & 2.74 & 0.3817 \\
\hline & 52 & 2.69 & 0.3293 \\
\hline & 54 & 2.71 & 0.2550 \\
\hline & 56 & 2.64 & 0.1888 \\
\hline
\end{tabular}

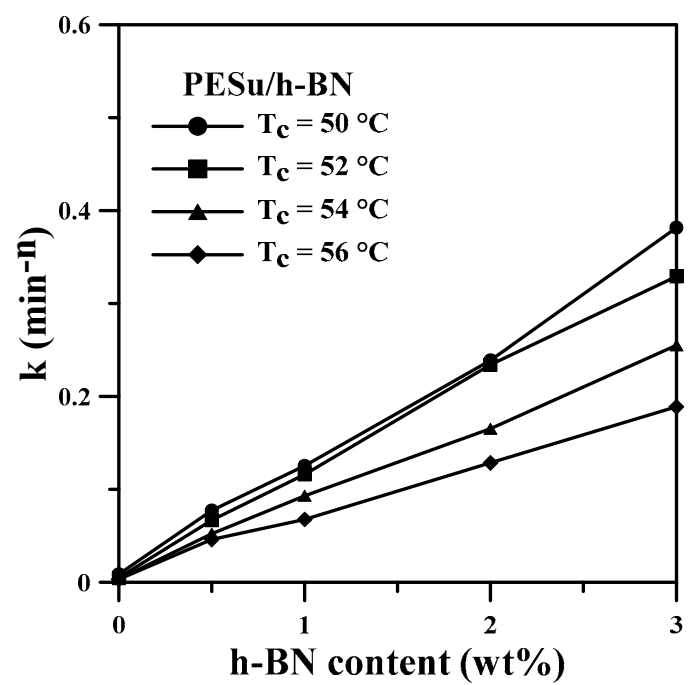

Figure 5. Plots showing $\mathrm{k}$ values of different crystallization temperatures for $\mathrm{PESu} / \mathrm{h}-\mathrm{BN}$ composites with the change of h-BN content in the composites.

\subsection{Spherulite Morphology Revealed by POM}

The spherulite morphologies were also observed in this study. The observation of spherulite was mainly performed to confirm the presence of the nucleation effect. The typical results of the morphologies recorded at the crystallization temperature of $50{ }^{\circ} \mathrm{C}$ are shown in Figure 6. It can be seen that, with the addition of h-BN, the spherulite morphologies obviously change. Firstly, by adding h-BN, the size of the spherulites was reduced. Secondly, when h-BN was present in composites, the number of spherulites significantly increased. The above two results can confirm the presence of the nucleation effect in the composites, and adding h-BN to PESu can introduce the crystallization nucleation effect. 


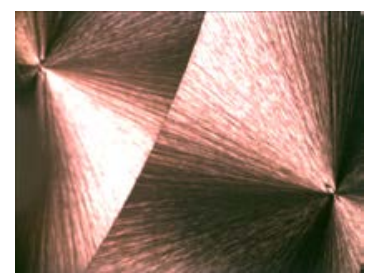

(a)

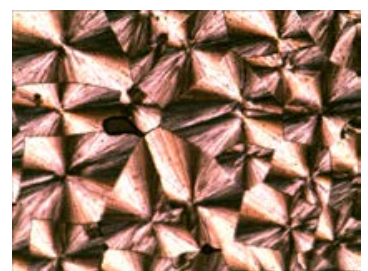

(b)

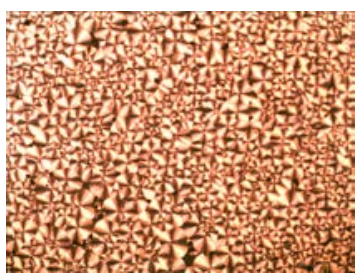

(c)
$800 \times 50 \mu \mathrm{m}$

Figure 6. Spherulite morphologies of PESu/h-BN composites when crystallized at $50^{\circ} \mathrm{C}$. The PESu/h-BN compositions are: (a) $100 / 0$; (b) $99 / 1$; and (c) $97 / 3$.

\subsection{Non-Isothermal Crystallization Behaviors of PESu/h-BN Composites}

Compared with isothermal crystallization, non-isothermal crystallization behavior is closer to the crystallization caused by the actual processing process. The non-isothermal crystallization experiments were carried out for the PESu/h-BN composites by the following procedures. All samples were heated to $130^{\circ} \mathrm{C}$ to erase the thermal history and then cooled at different cooling rates $\left(4,6,8,10^{\circ} \mathrm{C} / \mathrm{min}\right)$. The non-isothermal crystallization thermograms are summarized in Figure 7. The results for the different cooling rates of $4,6,8$, and $10^{\circ} \mathrm{C} / \mathrm{min}$ are displayed in Figure $7 \mathrm{a}-\mathrm{d}$, respectively. The phenomenon of the non-isothermal crystallization temperatures being located at a higher temperature for the composites in the presence of h-BN was confirmed. Furthermore, increasing the h-BN content caused the crystallization temperature to increase. The nucleation effect of h-BN affected the non-isothermal crystallization and also promoted its crystallization.

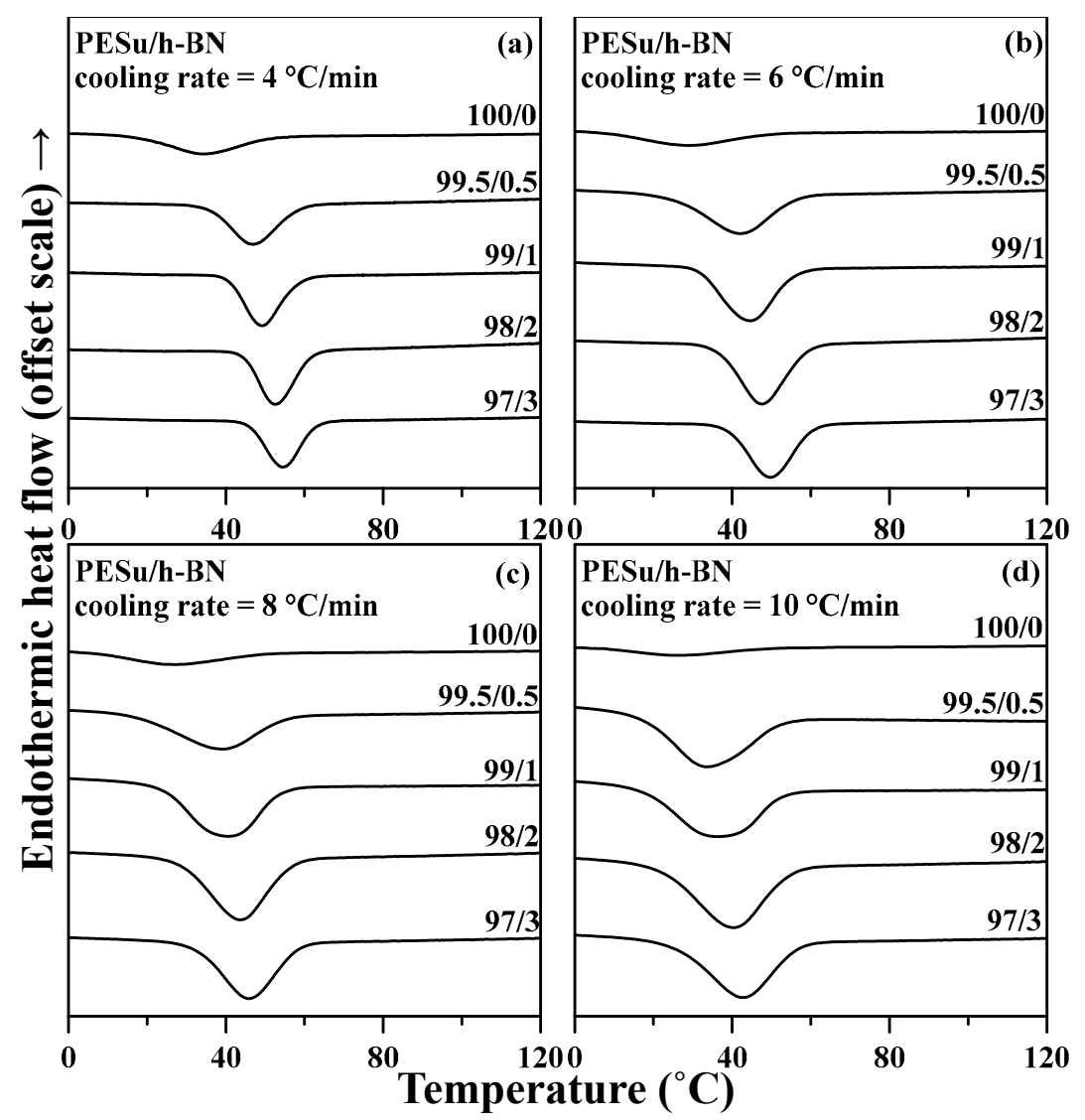

Figure 7. Non-isothermal crystallization thermograms of $\mathrm{PESu} / \mathrm{h}-\mathrm{BN}$ composites when the cooling rates are: (a) $4{ }^{\circ} \mathrm{C} / \mathrm{min}$; (b) $6{ }^{\circ} \mathrm{C} / \mathrm{min}$; (c) $8{ }^{\circ} \mathrm{C} / \mathrm{min}$; and (d) $10^{\circ} \mathrm{C} / \mathrm{min}$. 
The kinetic study of non-isothermal crystallization for polymer composites is also a critical issue to complete the investigation into non-isothermal crystallization. The nonisothermal crystallization kinetics can be systematically discussed using the model analysis method. One of the most useful model methods, the Mo model [38], was used herein. The equation of the Mo model is shown below:

$$
\log \Phi=-\operatorname{alog} \mathrm{t}+\log \mathrm{F}(\mathrm{T})
$$

where $\mathrm{F}(\mathrm{T})$ can reflect the crystallization rate; $\Phi$ is the cooling rate and a is the ratio of the Avrami index to Ozawa index. Figure 8 illustrates the Mo model results. It can be seen that the linear relationship between $\log \Phi$ and $\log t$ are displayed for the PESu/h-BN composites, indicating that the Mo model can be used to describe the non-isothermal crystallization behaviors of the PESu/h-BN composites. The related analysis results of the Mo model are summarized in Table 2. The results in Table 2 demonstrate that the $\mathrm{PESu} / \mathrm{h}$-BN composites presented lower $\mathrm{F}(\mathrm{T})$ values than $\mathrm{PESu}$; moreover, the increase in the h-BN content gradually decreased the $\mathrm{F}(\mathrm{T})$ value for the PESu/h-BN composites. A similar tendency is also demonstrated in Figure 9 with the $\mathrm{F}(\mathrm{T})$-vs-h-BN content plots. In general, the smaller $\mathrm{F}(\mathrm{T})$ value reflects the faster kinetic behavior of crystallization [39]. The relevant results of the Mo analysis for the PESu/h-BN composites demonstrated that the $\mathrm{PESu} / \mathrm{h}$-BN composites underwent faster crystallization than PESu. Similarly to the results of isothermal crystallization, the addition of h-BN would increase the non-isothermal crystallization rate. The main reason for the promoted crystallization kinetics might be attributed to the nucleation effect of h-BN in the composites.
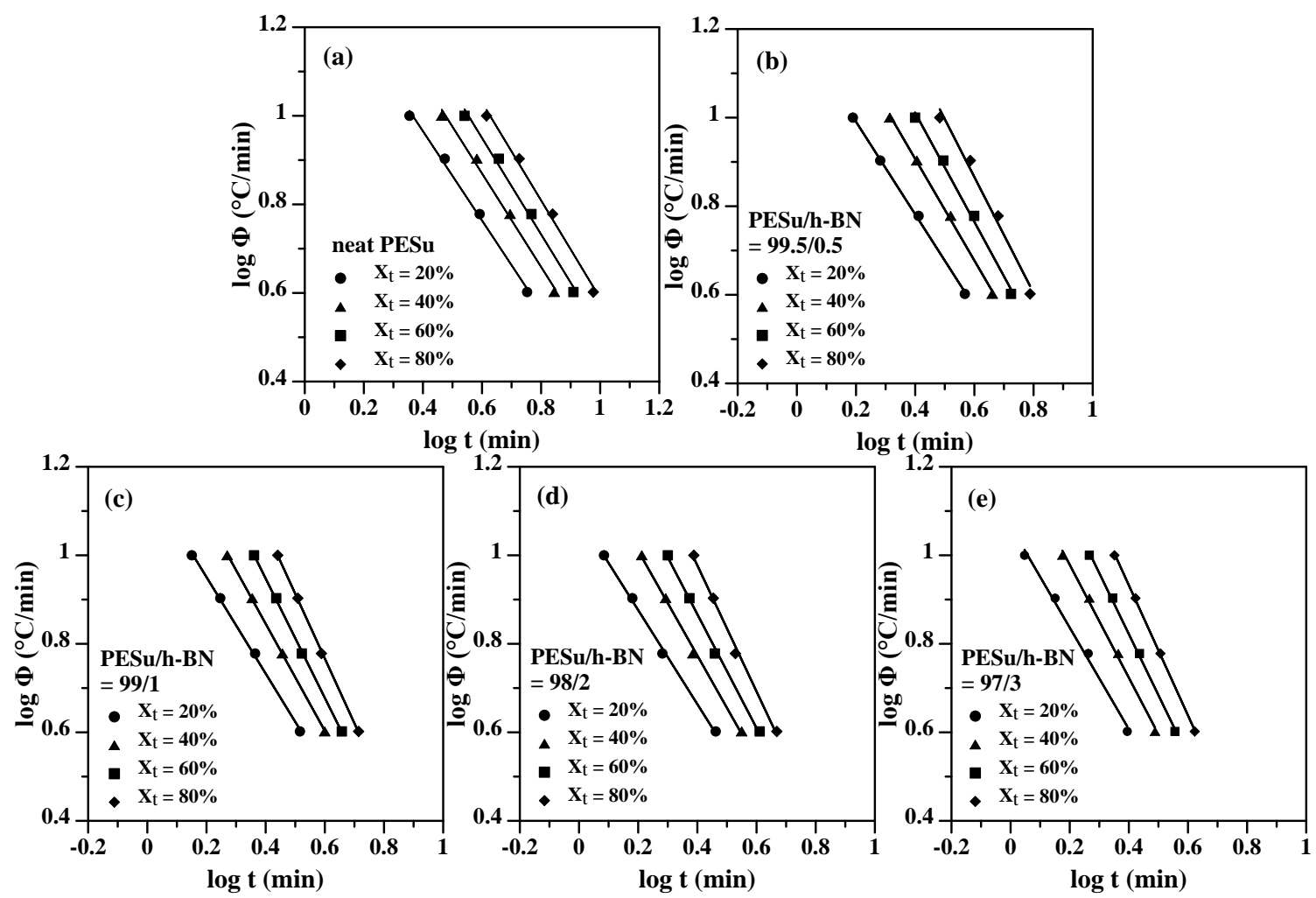

Figure 8. The fitting results of the Mo model on the non-isothermal crystallization behavior of various PESu/h-BN composites. The PESu/h-BN compositions (wt.\%) are: (a) 100/0; (b) 99.5/0.5; (c) 99/1; (d) 98/2; and (e) 97/3. 
Table 2. Non-isothermal crystallization parameters calculated by the Mo model for various PESu/hBN composites.

\begin{tabular}{ccc}
\hline PESu/h-BN (wt. $\%)$ & $\mathbf{X}_{\mathbf{t}} \mathbf{( \% )}$ & $\mathbf{F}(\mathbf{T})$ \\
\hline \multirow{3}{*}{$100 / 0$} & 20 & 23.37 \\
& 40 & 31.84 \\
& 60 & 40.08 \\
\multirow{2}{*}{$99.5 / 0.5$} & 80 & 49.37 \\
\hline & 20 & 15.83 \\
& 40 & 23.22 \\
$99 / 1$ & 60 & 31.83 \\
& 80 & 44.70 \\
\hline \multirow{2}{*}{$98 / 2$} & 20 & 14.75 \\
& 40 & 20.84 \\
& 60 & 29.88 \\
& 80 & 42.64 \\
\hline \multirow{2}{*}{$97 / 3$} & 20 & 12.27 \\
& 40 & 17.66 \\
& 60 & 24.05 \\
& 80 & 35.22 \\
\hline
\end{tabular}

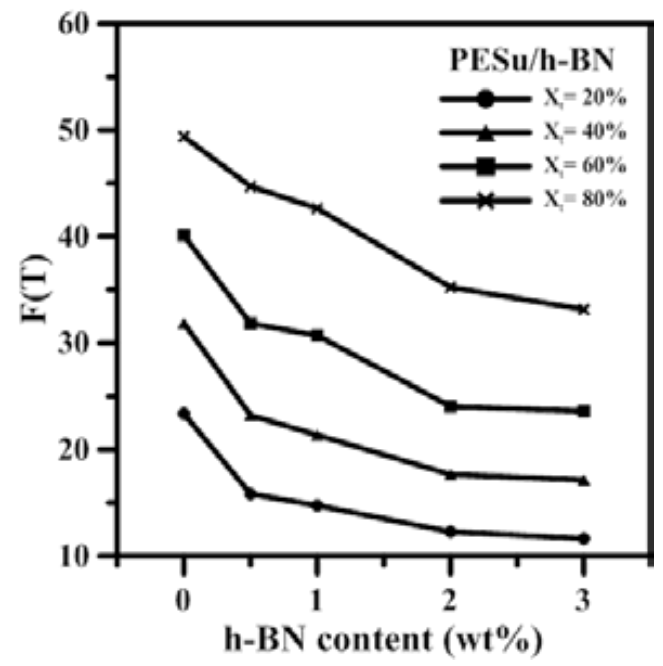

Figure 9. The $\mathrm{F}(\mathrm{T})$ values of $\mathrm{PESu} / \mathrm{h}-\mathrm{BN}$ composites that vary with h-BN content.

\subsection{WAXD Studies of PESu/h-BN Composites}

Figure 10 displays the WAXD patterns of the neat PESu, neat h-BN, and PESu/h-BN composites. The typical WAXD results from $\mathrm{PESu} / \mathrm{h}-\mathrm{BN}=99 / 1$ and $97 / 3$ composites were demonstrated. All composite samples were pre-crystallized at $50^{\circ} \mathrm{C}$ before WAXD measurements. In Figure 10, the main XRD peaks of neat PESu were at $2 \theta=20.1^{\circ}, 22.7^{\circ}$, and $23.2^{\circ}$. The crystal planes related to these angles are (021), (121) and (200) planes [40]. For the WAXD results of PESu/h-BN composites with different composites, we found that they had almost the same peak positions as neat PESu, indicating that the addition of h-BN would not influence the X-ray diffraction features and the crystalline structures of PESu. $\mathrm{H}-\mathrm{BN}$ in PESu/h-BN composites would effectively promote the crystallization rate of the composites as a nucleation agent without significantly changing the crystalline structures of PESu. It should also be noticed that the main diffraction peak of neat h-BN appeared at the position of $2 \theta=25.8^{\circ}$. In the PESu/h-BN composites, we found that the diffraction 
peak of h-BN was not obvious. This result may be attributed to the small amount of h-BN added in the PESu/h-BN composites.

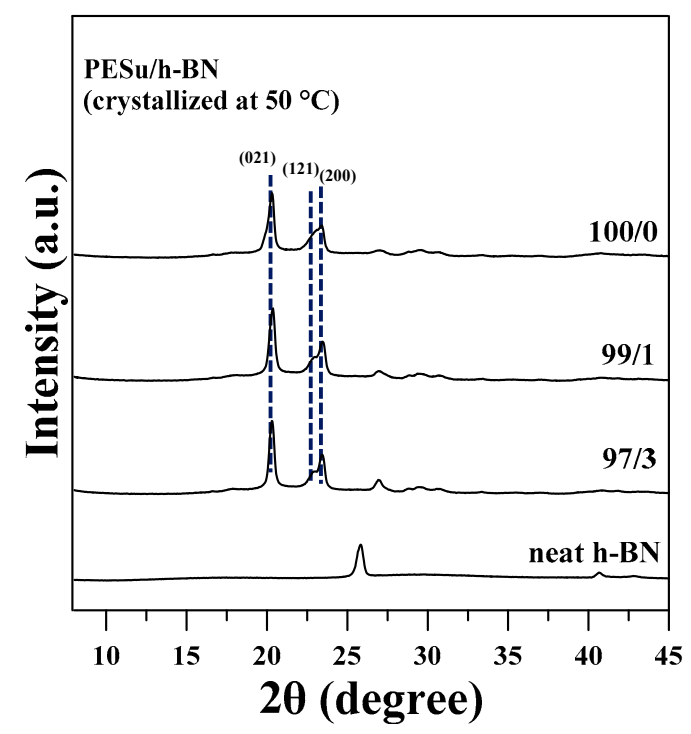

Figure 10. XRD patterns of the neat PESu, neat h-BN, and PESu/h-BN composites. Neat PESu and the PESu/h-BN composites were crystallized at $50^{\circ} \mathrm{C}$.

\section{Conclusions}

We conducted a series of crystallization analyses and characterizations on PESu/h$\mathrm{BN}$ composites. The Avrami equation can describe the kinetic behaviors of PESu/h-BN composites for their isothermal crystallization. The results of the $n$ value indicated that h-BN would not obviously affect PESu's crystallization mechanism. Furthermore, PESu/h$\mathrm{BN}$ composites showed the larger rate constant $\mathrm{k}$ than neat PESu. The larger rate constant $\mathrm{k}$ of the PESu/h-BN composites can represent that the PESu/h-BN composites can show a faster crystallization rate, and it can also indicate that adding h-BN can improve the slower crystallization of PESu to increase its crystallization rate so as to promote crystallization in the processing process. The kinetics of non-isothermal crystallization can be properly discussed by the Mo model. Regarding the results of the rate-related $\mathrm{F}(\mathrm{T})$ value, by adding $\mathrm{h}-\mathrm{BN}$ to the composites, a trend of showing a smaller $\mathrm{F}(\mathrm{T})$ value was observed. It can also be demonstrated that h-BN enhanced the crystallization kinetics. WAXD analyses displayed that h-BN did not alter PESu's crystalline structures. Higher resolution TEM and SEM confirmed that h-BN dispersed uniformly in PESu at the submicron scale. POM images demonstrated that the nucleation density was increased by adding h-BN. H-BN can promote the crystallization kinetics of PESu due to the nucleation effect.

Author Contributions: Performing major experiments and data analysis, H.-Y.T.; developing the research outline, designing the experiments, and writing most of the paper, L.-T.L.; investigations on the morphologies, T.-Y.W. All authors have read and agreed to the published version of the manuscript.

Funding: This research was funded by basic research grants of MOST 109-2221-E-035-079- and MOST 110-2221-E-035-025- from Taiwan's Ministry of Science and Technology (MOST).

Acknowledgments: The authors appreciate the financial support of basic research grants of MOST 109-2221-E-035-079- and MOST 110-2221-E-035-025- from Taiwan's Ministry of Science and Technology (MOST).

Conflicts of Interest: The authors declare no conflict of interest. 


\section{References}

1. Woo, E.M.; Yen, K.-C.; Yeh, Y.-T.; Wang, L.-Y. Biomimetically Structured Lamellae Assembly in Periodic Banding of Poly(ethylene adipate) Crystals. Macromolecules 2018, 51, 3845-3854. [CrossRef]

2. Ray, S.S.; Bousmina, M. Biodegradable polymers and their layered silicate nanocomposites: In greening the 21st century materials world. Prog. Mater. Sci. 2005, 50, 962-1079. [CrossRef]

3. Santagata, G.; Valerio, F.; Cimmino, A.; Poggetto, G.D.; Masi, M.; Di Biase, M.; Malinconico, M.; Lavermicocca, P.; Evidente, A. Chemico-physical and antifungal properties of poly(butylene succinate)/cavoxin blend: Study of a novel bioactive polymeric based system. Eur. Polym. J. 2017, 94, 230-247. [CrossRef]

4. Khan, A.K.; Ho, J.C.S.; Roy, S.; Liedberg, B.; Nallani, M. Facile Mixing of Phospholipids Promotes Self-Assembly of LowMolecular-Weight Biodegradable Block Co-Polymers into Functional Vesicular Architectures. Polymers 2020, 12, 979. [CrossRef]

5. Nanaki, S.; Viziridou, A.; Zamboulis, A.; Kostoglou, M.; Papageorgiou, G.Z.; Bikiaris, D.N. New Biodegradable Poly(l-lactide)Block-Poly(propylene adipate) Copolymer Microparticles for Long-Acting Injectables of Naltrexone Drug. Polymers 2020, $12,852$. [CrossRef]

6. Corres, M.Á.; Mayor, Á.; Sangroniz, A.; del Río, J.; Iriarte, M.; Etxeberria, A. Blends based on biodegradable poly(caprolactone) with outstanding barrier properties for packaging applications: The role of free volume and interactions. Eur. Polym. J. 2020, 135, 109869. [CrossRef]

7. Gu, J.-D. Microbiological deterioration and degradation of synthetic polymeric materials: Recent research advances. Int. Biodeterior. Biodegrad. 2003, 52, 69-91. [CrossRef]

8. Woo, E.M.; Lugito, G. Origins of periodic bands in polymer spherulites. Eur. Polym. J. 2015, 71, 27-60. [CrossRef]

9. Courgneau, C.; Ducruet, V.; Avérous, L.; Grenet, J.; Domenek, S. Nonisothermal crystallization kinetics of poly(lactide)-effect of plasticizers and nucleating agent. Polym. Eng. Sci. 2013, 53, 1085-1098. [CrossRef]

10. Gumede, T.P.; Luyt, A.S.; Hassan, M.K.; Pérez-Camargo, R.A.; Tercjak, A.; Müller, A.J. Morphology, Nucleation, and Isothermal Crystallization Kinetics of Poly( $\varepsilon$-caprolactone) Mixed with a Polycarbonate/MWCNTs Masterbatch. Polymers 2017, 9, 709. [CrossRef] [PubMed]

11. Qiu, Z.; Li, Z. Effect of Orotic Acid on the Crystallization Kinetics and Morphology of Biodegradable Poly(l-lactide) as an Efficient Nucleating Agent. Ind. Eng. Chem. Res. 2011, 50, 12299-12303. [CrossRef]

12. Tang, L.; Qiu, Z. Enhanced nonisothermal and isothermal cold crystallization kinetics of biodegradable poly(l-lactide) by trisilanolisobutyl-polyhedral oligomeric silsesquioxanes in their nanocomposites. J. Appl. Polym. Sci. 2016, 133. [CrossRef]

13. Hua, L.; Kai, W.H.; Inoue, Y. Crystallization behavior of poly(E-caprolactone)/graphite oxide composites. J. Appl. Polym. Sci. 2007, 106, 4225-4232. [CrossRef]

14. Chen, Y.-A.; Wu, T.-M. Crystallization Kinetics of Poly(1,4-butylene adipate) with Stereocomplexed Poly(lactic acid) Serving as a Nucleation Agent. Ind. Eng. Chem. Res. 2014, 53, 16689-16695. [CrossRef]

15. Prasannan, A.; Bich-Tram, T.-L.; Hsu, D.-Y.; Hong, P.-D.; Pan, G.-R. Nucleation effects of $\alpha$-cyclodextrin inclusion complexes on the crystallization behavior of biodegradable poly(1,4-butylene adipate). CrystEngComm 2013, 15, 5119-5126. [CrossRef]

16. Bosq, N.; Aht-Ong, D. Isothermal and non-isothermal crystallization kinetics of poly(butylene succinate) with nanoprecipitated calcium carbonate as nucleating agent. J. Therm. Anal. Calorim. 2018, 132, 233-249. [CrossRef]

17. Lee, L.-T.; Hsu, C.-Y.; Hung, S.-P. Promoted crystallization kinetics of biodegradable poly(butylene succinate) by a nucleation agent of green chemical. J. Polym. Res. 2019, 26, 1-9. [CrossRef]

18. Tang, J.; Li, L.; Wang, X.; Yang, J.; Liang, X.; Li, Y.; Ma, H.; Zhou, S.; Wang, J. Tailored crystallization behavior, thermal stability, and biodegradability of poly(ethylene adipate): Effects of a biocompatible diamide nucleating agent. Polym. Test. 2020, 81, 106116. [CrossRef]

19. Papageorgiou, G.Z.; Terzopoulou, Z.; Achilias, D.S.; Bikiaris, D.N.; Kapnisti, M.; Gournis, D. Biodegradable poly(ethylene succinate) nanocomposites. Effect of filler type on thermal behaviour and crystallization kinetics. Polymers 2013, 54, 4604-4616. [CrossRef]

20. Morales-Huerta, J.; De Ilarduya, A.; Muñoz-Guerra, S. A green strategy for the synthesis of poly(ethylene succinate) and its copolyesters via enzymatic ring opening polymerization. Eur. Polym. J. 2017, 95, 514-519. [CrossRef]

21. Papageorgiou, G.Z.; Terzopoulou, Z.; Tsanaktsis, V.; Achilias, D.; Triantafyllidis, K.; Diamanti, E.K.; Gournis, D.; Bikiaris, D.N. Effect of graphene oxide and its modification on the microstructure, thermal properties and enzymatic hydrolysis of poly(ethylene succinate) nanocomposites. Thermochim. Acta 2015, 614, 116-128. [CrossRef]

22. Tang, L.; Qiu, Z. Crystallization Kinetics and Morphology of Biodegradable Poly(ethylene succinate)/Octavinyl-Polyhedral Oligomeric Silsesquioxanes Nanocomposites. Ind. Eng. Chem. Res. 2014, 53, 11365-11370. [CrossRef]

23. Jing, X.; Qiu, Z. Influence of Thermally Reduced Graphene Low-Loadings on the Crystallization Behavior and Morphology of Biodegradable poly(ethylene succinate). Ind. Eng. Chem. Res. 2014, 53, 498-504. [CrossRef]

24. Vasileiou, A.A.; Papageorgiou, G.Z.; Kontopoulou, M.; Docoslis, A.; Bikiaris, D. Covalently bonded poly(ethylene succinate) $/ \mathrm{SiO}_{2}$ nanocomposites prepared by in situ polymerisation. Polymer 2013, 54, 1018-1032. [CrossRef]

25. Ray, S.S.; Makhatha, M.E. Thermal properties of poly(ethylene succinate) nanocomposite. Polymers 2009, 50, 4635-4643. [CrossRef]

26. Teng, S.; Jiang, Z.; Qiu, Z. Effect of different POSS structures on the crystallization behavior and dynamic mechanical properties of biodegradable Poly(ethylene succinate). Polymers 2019, 163, 68-73. [CrossRef] 
27. Li, Z.; Kong, J.; Han, L.; Zhang, H.; Dong, L. Effect of crystallinity on the thermal conductivity of poly(3-hydroxybutyrate)/BN composites. Polym. Bull. 2017, 75, 1651-1666. [CrossRef]

28. Refaa, Z.; Boutaous, M.; Xin, S.; Fulchiron, R. Synergistic effects of shear flow and nucleating agents on the crystallization mechanisms of Poly (Lactic Acid). J. Polym. Res. 2017, 24, 18. [CrossRef]

29. Gumede, T.P.; Luyt, A.S.; Camargo, R.A.P.; Tercjak, A.; Müller, A.J. Morphology, Nucleation, and Isothermal Crystallization Kinetics of Poly(Butylene Succinate) Mixed with a Polycarbonate/MWCNT Masterbatch. Polymers 2018, 10, 424. [CrossRef] [PubMed]

30. Arjmandi, R.; Hassan, A.; Eichhorn, S.J.; Haafiz, M.K.M.; Zakaria, Z.; Tanjung, F. Enhanced ductility and tensile properties of hybrid montmorillonite/cellulose nanowhiskers reinforced polylactic acid nanocomposites. J. Mater. Sci. 2015, 50, 3118-3130. [CrossRef]

31. Jiang, X.; Weng, Q.; Wang, X.-B.; Li, X.; Zhang, J.; Golberg, D.; Bando, Y. Recent Progress on Fabrications and Applications of Boron Nitride Nanomaterials: A Review. J. Mater. Sci. Technol. 2015, 31, 589-598. [CrossRef]

32. Düzcükoğlu, H.; Ekinci, Ş.; Sahin, Ö.S.; Avci, A.; Ekrem, M.; Ünaldi, M. Enhancement of Wear and Friction Characteristics of Epoxy Resin by Multiwalled Carbon Nanotube and Boron Nitride Nanoparticles. Tribol. Trans. 2015, 58, 635-642. [CrossRef]

33. Farshid, B.; Lalwani, G.; Mohammadi, M.S.; Simonsen, J.; Sitharaman, B. Boron nitride nanotubes and nanoplatelets as rein-forcing agents of polymeric matrices for bone tissue engineering. J. Biomed. Mater. Res. Part B 2017, 105, 406-419. [CrossRef]

34. Zhang, X.; Zhang, X.; Yang, M.; Yang, S.; Wu, H.; Guo, S.; Wang, Y. Ordered multilayer film of (graphene oxide/polymer and boron nitride/polymer) nanocomposites: An ideal EMI shielding material with excellent electrical insulation and high thermal conductivity. Compos. Sci. Technol. 2016, 136, 104-110. [CrossRef]

35. Wang, H.; Su, X.; Song, T.; Li, Z.; Zhao, Y.; Lou, H.; Wang, J. Scalable exfoliation and dispersion of few-layer hexagonal boron nitride nanosheets in NMP-salt solutions. Appl. Surf. Sci. 2019, 488, 656-661. [CrossRef]

36. Wang, L.; Wang, X.; Zhu, W.; Chen, Z.; Pan, J.; Xu, K. Effect of nucleation agents on the crystallization of poly (3-hydroxybutyrateco-4-hydroxybutyrate) (P3/4HB). J. Appl. Polym. Sci. 2010, 116, 1116-1123. [CrossRef]

37. Hsu, T.-C.; Lee, L.-T.; Wu, X.-Y. Investigations on Novel Ternary Green Polymer Composite. Processes 2019, 8, 31. [CrossRef]

38. Ahmed, J.; Luciano, G.; Maggiore, S. Nonisothermal crystallization behavior of polylactide/polyethylene glycol/graphene oxide nanosheets composite films. Polym. Compos. 2020, 41, 2108-2119. [CrossRef]

39. Lee, L.-T.; Ke, Y.-L. Superior Crystallization Kinetics Caused by the Remarkable Nucleation Effect of Graphene Oxide in Novel Ternary Biodegradable Polymer Composites. ACS Omega 2020, 5, 30643-30656. [CrossRef] [PubMed]

40. Qiu, S.; Zhang, K.; Su, Z.; Qiu, Z. Thermal behavior, mechanical and rheological properties, and hydrolytic degradation of novel branched biodegradable poly(ethylene succinate) copolymers. Polym. Test. 2018, 66, 64-69. [CrossRef] 